\title{
Immunoglobulin E and systemic lupus erythematosus
}

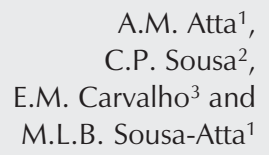

A.M. Atta ${ }^{1}$,

C.P. Sousa ${ }^{2}$,

E.M. Carvalho ${ }^{3}$ and

M.L.B. Sousa-Atta ${ }^{1}$

\author{
'Departamento de Análises Clínicas e Toxicológicas, Faculdade de Farmácia, \\ ${ }^{2}$ Programa de Pós-Graduação em Imunologia, and \\ ${ }^{3}$ Serviço de Imunologia, Hospital Universitário Prof. Edgard Santos, \\ Universidade Federal da Bahia, Salvador, BA, Brasil
}

Correspondence

A.M. Atta

Departamento de Análises Clínicas

e Toxicológicas

Faculdade de Farmácia, UFBA

Rua Geremoabo, s/n

40171-970 Salvador, BA

Brasil

Fax +55-71-332-1580

E-mail: ajatta@ig.com.br

Received May 8, 2003

Accepted June 9, 2004

\begin{abstract}
Systemic lupus erythematosus (SLE) is an autoimmune disease characterized by intense polyclonal production of autoantibodies and circulating immune complexes. Some reports have associated SLE with a Th2 immune response and allergy. In the present study 21 female patients with SLE were investigated for total IgE and IgE antibodies to dust house aeroallergens by an automated enzymelinked fluorescent assay, and were also evaluated for antinuclear $\operatorname{IgE}$ autoantibodies by a modified indirect immunofluorescence test using HEp- 2 cells as antigen substrate. Additionally, immunocapture ELISA was used to investigate serum anti-IgE IgG autoantibodies. Serum IgE above $150 \mathrm{IU} / \mathrm{ml}$, ranging from 152 to $609 \mathrm{IU} / \mathrm{ml}$ (median = $394 \mathrm{IU}$ $\mathrm{IgE} / \mathrm{ml}$ ), was observed in 7 of 21 SLE patients (33\%), 5 of them presenting proteinuria, urinary cellular casts and augmented production of anti-dsDNA antibodies. While only 2 of 21 SLE patients $(9.5 \%)$ were positive for IgE antibodies to aeroallergens, all 10 patients with respiratory allergy (100\%) from the atopic control group ( 3 males and 7 females), had these immunoglobulins. SLE patients and healthy controls presented similar anti-IgE IgG autoantibody titers $(X=0.37 \pm 0.20$ and $0.34 \pm 0.18$, respectively), differing from atopic controls $(0.94 \pm 0.26)$. Antinuclear IgE autoantibodies were detected in 17 of $21(81 \%)$ sera from SLE patients, predominating the fine speckled pattern of fluorescence, that was also observed in IgG-ANA. Concluding, SLE patients can present increased IgE levels and antinuclear IgE autoantibodies without specific clinical signs of allergy or production of antiallergen IgE antibodies, excluding a possible association between SLE and allergy.
\end{abstract}

Systemic lupus erythematosus (SLE) is an autoimmune disease characterized by intense polyclonal activation of B lymphocytes and vigorous production of autoantibodies. This disease is associated with patient race and socioeconomic status and courses with chronic systemic inflammation,
Key words - Systemic lupus erythematosus

- Antinuclear IgE antibody

- Allergy

- $\lg \mathrm{G}$ anti-lgE

- IgE mediated mainly by deposits of immune complexes in different organs and systems, and high production of autoantibodies with specificity for different nuclear antigens. Some antinuclear autoantibodies are associated with clinical aspects of SLE, such as anti-dsDNA antibodies, which show a close relationship 
with impairment of renal function, and also anti-SSA/Ro and anti-SSB/La antibodies, which are more frequently detected in patients with cutaneous manifestations and photosensitivity $(1,2)$.

SLE is characterized by a Th2 immune response, presenting significant interleukin 10 (IL-10) production (1). Additionally, some reports have shown increased IgE production in this disease and have associated SLE with allergy (3-8). In addition, the occurrence of anti-IgE $\operatorname{IgG}$ autoantibodies has been demonstrated in SLE patients with articular involvement, lymphadenopathy and anti-DNA antibodies (9). The human Th2 immune response is mainly observed in atopy and in some parasitic diseases, being characterized by significant production of IL-4, IL10 and IgE antibodies. An increased serum IgE concentration has been associated with SLE activity and lupus nephritis $(4,6,10,11)$. However, the occurrence of antinuclear IgE autoantibodies in SLE patients has not been appropriately investigated. To date, there are only two isolated reports showing $\mathrm{IgE}$ antinuclear autoantibodies in SLE patients: one using rat liver tissue as antigen substrate, which does not have important extractable nuclear antigens such as SSA/Ro, and the other obtained with granulocyte nuclei $(12,13)$.

The aim of the present study was to evaluate the $\operatorname{IgE}$ immune response in Brazilian SLE patients by determining the serum concentration of this immunoglobulin, the occurrence of specific IgE antibodies to aeroallergens and nuclear antigens, and also the presence of anti-IgE $\operatorname{IgG}$ autoantibodies in patient sera.

Serum samples from 21 women ( 15 to 60 years old), previously classified as SLE patients using the revised criteria of the American College of Rheumatology (14) were evaluated. Patient sera were obtained before therapy and examined for SLE laboratory criteria (IgG-ANA, anti-dsDNA autoantibodies, urinalysis, and antiphospholipid anti- bodies). However, a few patients were already using corticosteroids. All patients were seropositive for IgG-ANA by conventional indirect immunofluorescent test (IFAT) using HEp-2 cells as antigen substrate. Seventeen presented antinuclear antibody titers of 1/160 and more. In addition, 19 of 21 (86\%) patients had serum anti-dsDNA autoantibodies, presenting a $95 \%$ confidence interval from 311 to $862 \mathrm{IU}$ antibody/ml, as determined by indirect ELISA with 50 IU antibody/ml as the cut-off (Hemagen Diagnostics Inc., Columbia, MD, USA). All SLE patients were negative for intestinal parasitic infection by helminths or protozoa, as assessed by serial exams of three stool samples. Eleven of 21 subjects reported sporadic and nonspecific episodes of mild adverse drug reactions characterized mainly by dermatological manifestations like erythema, and 8 of 21 had laboratory findings of renal disorders such as hematuria, cellular casts and proteinuria.

Sera from 10 atopic patients, 3 males and 7 females, with a clinical diagnosis of respiratory allergy and presenting both positive skin prick tests and $\operatorname{IgE}$ antibody reactivity to common aeroallergens in vitro were included in the immunoassay to evaluate serum antiIgE IgG autoantibodies. In addition, sera from 20 healthy individuals, 8 males and 12 females ranging in age from 15 to 60 years, were used as negative control in this assay and also in the IFAT to investigate antinuclear IgE antibodies. These subjects did not have a clinical history of atopy or specific $\mathrm{IgE}$ antibodies to aeroallergens.

Serum IgE concentration was determined by enzyme-linked fluorescent assay (ELFA) using the Vidas 30 Immunoanalyzer from bioMérieux (Rio de Janeiro, RJ, Brazil). The International Reference Value of 150 IU of $\mathrm{IgE} / \mathrm{ml}$ was used in the evaluation of the results.

$\operatorname{IgE}$ antibodies to a panel of aeroallergens consisting of proteins from pollens, mites, molds, dog and cat epithelia, and also from 
cockroaches were investigated by ELFA using the Stallertest immunoassay from the bioMeriéux and a Vidas 30 Immunoanalyzer. The cut-off of 0.70 relative fluorescence value (RFV) of this test was used.

IgE immunocapture ELISA using polystyrene microplates containing wells coated with $500 \mathrm{ng}$ of goat IgG anti-human IgE and a goat IgG anti-human IgG peroxidase conjugate from the same source was used to detect anti-IgE IgG autoantibodies (15). This assay detects IgG autoantibodies that recognize IgE epitopes, which are exposed after the capture of this immunoglobulin by goat IgG anti-human IgE adsorbed to the solid phase. Briefly, $100 \mu \mathrm{l}$ of sera diluted 1:2 in phosphate buffered-saline (PBS), $\mathrm{pH}$ 7.4, containing $1 \%$ bovine serum albumin and $0.05 \%$ Tween 20 was incubated for $1 \mathrm{~h}$ at room temperature in the wells to capture IgE. The wells were washed with PBS and the immune interaction of anti-IgE autoantibodies with $\mathrm{IgE}$ epitopes was detected after incubation with $100 \mu$ l of the diluted conjugate under the same conditions. The wells were washed again and the reactions were developed with hydrogen peroxide plus 3,3',5,5'-tetramethylbenzidine (TMB) for 30 min as usual, stopped with $2 \mathrm{~N} \mathrm{HCl}$ and determined at 450-600 nm using a Diamedix BP-12 (Miami, FL, USA) microassay apparatus.

IgE antinuclear antibodies were investigated by an IFAT carried out with fixed epithelial HEp-2 cell slides purchased from a commercial source (DTS, Rio de Janeiro, RJ, Brazil). In this IFAT, sera were first depleted of $\operatorname{IgG}$ by $1 / 5$ dilution in a purified solution of anti-human IgG sheep IgG (RF Absorbent $^{\mathrm{TM}}$, DADE-Behring, Marburg, Germany) as recommended for IFAT. After centrifugation to sediment IgG immune complexes, $25 \mu \mathrm{l}$ of the IgG-depleted supernatants was incubated with HEp- 2 cell smears for $18 \mathrm{~h}$ at $4^{\circ} \mathrm{C}$ in a humid chamber to carry out the primary immune reaction. The slides were washed three times with PBS $(150 \mathrm{mM}$
$\mathrm{NaCl}$ plus $10 \mathrm{mM}$ sodium phosphate, $\mathrm{pH}$ 7.2) and the cell smears submitted to a second incubation with $25 \mu \mathrm{l}$ of properly diluted goat IgG anti-human IgE FITC conjugate (Sigma, St. Louis, MO, USA) in PBS containing $0.01 \%$ Evans blue, for $2 \mathrm{~h}$ at $37^{\circ} \mathrm{C}$. After a third wash with PBS, the cell nuclei were examined at $400 \mathrm{X}$ magnification under an Olympus BHF (Shibuya, Tokyo, Japan) fluorescence microscope after the addition of mounting medium ( $90 \%$ glycerol in $100 \mathrm{mM}$ carbonate buffer, $\mathrm{pH} 9.0$ ). The results of the reactions were reported as positive or negative, and the pattern of fluorescence was described as advised for $\mathrm{IgG}$ antinuclear antibodies (16).

The Prism PC program (version 1.00; GraphPad Software Inc., 1994) and the chisquare, Kruskal-Wallis and Mann-Whitney tests were used for statistic analysis.

Increased serum IgE concentration above the International Reference Value of 150 IU/ $\mathrm{ml}$ was observed in 7 of 21 (33\%) SLE patients. In this group, IgE levels ranged from 152 to $609 \mathrm{IU} / \mathrm{ml}$ (median = $394 \mathrm{IU}$ $\mathrm{IgE} / \mathrm{ml}$ ) and laboratory urinary findings of renal disorders such as persistent proteinuria, hematuria and cellular casts was documented in 5 of the 7 positive patients. $\operatorname{IgE}$ was increased in the renal group (ranged from 152 to $582 \mathrm{IU} / \mathrm{ml}$, median = $190 \mathrm{IU}$ ) when compared with the patients without renal disease, who presented a range from 10 to 609 and a median of $61 \mathrm{IU} / \mathrm{ml}\left(\chi^{2}=0.05\right.$, significant level). The serum concentration of anti-dsDNA antibodies was also augmented in the renal SLE group, that presented a median of $777 \mathrm{IU}$ antibodies $/ \mathrm{ml}$ as compared to 175 IU displayed by SLE patients without renal disorders $(\mathrm{P}=0.01$, Mann-Whitney test; Figure 1).

Specific IgE antibodies to aeroallergens were observed in 2 of 21 (9.5\%) SLE patients, one of whom presented a renal disorder. The serum level of anti-IgE IgG autoantibodies in the SLE group $(X=0.37 \pm 0.20$, mean $\pm \mathrm{SD}$ ) was similar to that of healthy 
controls $(X=0.34 \pm 0.18)$, but a higher titer of anti-IgE IgG autoantibodies of $0.94 \pm 0.26$ was observed in the atopic group $(\mathrm{P}<0.05$, Kruskal-Wallis test; Table 1).

Antinuclear IgE autoantibodies were detected by IFAT in 17 of 21 (81\%) sera from SLE patients, with 6 of them presenting renal disorders. A fine speckled pattern of nuclear fluorescence was observed in sera from 15 patients, while the other two reacted with antigens of the nuclear membrane. There was no correlation between high serum IgE concentration and positive IgE-ANA. However, positive IgE-ANA was more frequent in sera presenting an IgG-ANA titer of 160 or more.

We demonstrate here that Brazilian SLE

Figure 1. Titers of anti-dsDNA autoantibodies in systemic lupus erythematosus (SLE) patients without renal involvement $(\mathrm{N}=12)$ and with renal involvement (Renal SLE, $N=7$ ). A median of 175 IU antibody/ml with 25 and $75 \%$ of 55 and 503 IU antibody/ml, respectively, was observed for the SLE group, whereas a median of $777 \mathrm{IU}$ antibody/ml, and 25 and $75 \%$ of 323 and 1433 were observed in the SLE patients with renal involvement. The maximum and minimum titers are indicated by bars.

Table 1. Serological findings in SLE patients evaluated for IgE immune response.

\begin{tabular}{lccc}
\hline Immune evaluation & \multicolumn{3}{c}{ Clinical group } \\
\cline { 2 - 4 } & SLE $(\mathrm{N}=21)$ & Atopy (N=10) & Healthy (N = 20) \\
\hline Total IgE (IU/mI) & 394 & $\mathrm{ND}$ & $<150^{*}$ \\
Anti-allergen IgE antibody & $2 / 21(9.5 \%)$ & $10 / 10(100 \%)$ & $0 / 20(0 \%)$ \\
Anti-IgE IgG autoantibody & $0.37 \pm 0.20$ & $0.94 \pm 0.26$ & $0.34 \pm 0.18$ \\
Antinuclear IgG autoantibody & $21 / 21(100 \%)$ & $\mathrm{ND}$ & $0 / 20(0 \%)$ \\
Antinuclear IgE autoantibody & $17 / 21(81 \%)$ & $\mathrm{ND}$ & $0 / 20(0 \%)$ \\
\end{tabular}

* International Reference Value for adolescent and adult subjects. IgE concentration (reported as median) and antiallergen IgE antibodies were determined by enzymelinked fluorescent assay using the automated analyzer Vidas 30 from bioMérieux. Antinuclear IgG and IgE autoantibodies were investigated by indirect immunofluorescent test using HEp-2 cells as nuclear antigen substrate. Anti-lgE IgG autoantibodies were detected using an immunocapture ELISA, being reported as mean \pm SD. The frequencies of antinuclear IgG and IgE autoantibodies and antiallergen IgE antibodies are represented by percent positivity. ND = not determined. patients can present increased serum $\operatorname{IgE}$ concentration, as previously reported for American and Hungarian SLE patients (4,5, 11). This mild elevation of serum $\operatorname{IgE}$ was not associated with intestinal parasitic diseases or serological findings of common respiratory allergy, as demonstrated by the negative results of 19 of 21 SLE patients evaluated by specific IgE immunoassay for usual aeroallergens. On the other hand, the 2 SLE patients having IgE antibodies to aeroallergens did not report any history of adverse drug reactions. These findings differed from those of previous studies reporting evidence of atopy in SLE patients, obtained indirectly through application of allergy-directed questionnaires $(3,4,10)$. Moreover, a recent and controlled study evaluating the immune response of SLE patients to skin prick tests with aeroallergens also showed a complete lack of association between systemic lupus erythematosus and allergy (17).

A possible pathogenic role of $\operatorname{IgE}$ antibodies in lupus nephritis has been claimed by some research groups that observed an increased serum concentration of this immunoglobulin in renal SLE patients $(4,10)$. Additionally, IgE was detected in glomerular deposits of immune complexes by immunofluorescence assays of kidney biopsies from renal SLE subjects $(18,19)$. In the present study, 5 of 8 SLE patients with laboratory findings of renal disorders such as proteinuria, hematuria and urinary cellular casts had high serum IgE concentrations and 6 of them had antinuclear IgE autoantibodies. However, there was no association between renal disorders and antinuclear IgE seropositivity when compared with the SLE group without renal involvement. SLE renal patients produced more anti-dsDNA antibodies than SLE subjects without renal disorders, confirming a close relationship between the level of these antibodies and renal manifestations of SLE (20).

Anti-IgE autoantibody concentration was similar in both SLE and healthy control 
groups, differing from the atopic one, that presented elevated levels of these antibodies. These results show that the production of anti-IgE IgG autoantibodies is apparently unaffected by the intense polyclonal activation of B lymphocytes observed in SLE.

We have demonstrated for the first time that antinuclear $\operatorname{IgE}$ autoantibodies can be frequently demonstrated in SLE patients, with the predominance of a fine speckled pattern of fluorescence in both IgE and IgG-ANA suggesting that both isotypes of autoanti- bodies recognize common extractable nuclear antigens. Apparently, the production of $\operatorname{IgE}$ antinuclear autoantibodies in SLE is controlled by specific autoimmune recognition and is not affected by polyclonal activation of B-lymphocytes. Such conclusion is supported in this study by a consistent lack of production of antiallergen $\mathrm{IgE}$ antibodies in SLE patients and by the occurrence of IgEANA in individuals having normal and low serum IgE concentrations.

\section{References}

1. Mok CC \& Lau CS (2003). Pathogenesis of systemic lupus erythematosus. Journal of Clinical Pathology, 56: 481-490.

2. Hahn BH (1997). Pathogenesis of systemic lupus erythematosus. In: Kelley WN, Harris Jr ED, Ruddy S \& Sledge CB (Editors), Textbook of Rheumatology. 15th edn. Saunders Company, Philadelphia, PA, USA.

3. Diumenjo MS, Lisanti M, Vallés R \& Rivero I (1985). Allergic manifestations of systemic lupus erythematosus. Allergologia et Immunopathologia, 13: 323-326.

4. Goldman JA, Klimek GA \& Ali R (1976). Allergy in systemic lupus erythematosus. IgE level and reaginic phenomenon. Arthritis and Rheumatism, 19: 669-676.

5. Mikecz K, Sonkoly I, Meszaros C \& Szegedi G (1985). Serum IgE in systemic lupus erythematosus. Acta Medica Hungarica, 42: 59-65.

6. Petri M \& Allbritton J (1992). Antibiotic allergy in systemic lupus erythematosus: a case control study. Journal of Rheumatology, 19: 265-269.

7. Sequeira JF, Cesic D, Keser G, Bukelica M, Karanagnostis S, Khamashta MA \& Hughes GRV (1993). Allergy disorders in systemic lupus erythematosus. Lupus, 2: 187-191.

8. Shahar E \& Lorber M (1997). Allergy and SLE: common and variable. Israel Journal of Medical Sciences, 33: 147-149.

9. Gruber BL, Kaufman LD, Marchese MJ, Roth W \& Kaplan AP (1988). Anti-IgE autoantibodies in systemic lupus erythematosus. Arthritis and Rheumatism, 31: 1000-1006.

10. Laurent J, Lagrue G \& Sobel A (1986). Increased serum IgE levels in patients with lupus nephritis. American Journal of Nephrology, 6: 413-414.

11. Rebhun J, Quismorio F, Dubois E \& Heiner DC (1983). Systemic lupus erythematosus activity and IgE. Annals of Allergy, 50: 34-36.

12. Barone C, Bartoloni C, Gentiloni N, Grieco A \& Flamini A (1981) Systemic lupus erythematosus with only IgE-class antinuclear antibodies. Arthritis and Rheumatism, 24: 1441-1443.

13. Permin $H$ \& Wiik $A$ (1978). The prevalence of lgE antinuclear antibodies in rheumatoid arthritis and systemic lupus erythematosus. Acta Pathologica et Microbiologica Scandinavica [C], 86: 245-249.

14. Hochberg MC (1997). Updating the American College of Rheumatology revised criteria for the classification of systemic lupus erythematosus. Arthritis and Rheumatism, 40: 1725.

15. Atta AM, Sousa-Atta MLB, D'Oliveira A, Almeida RP, Araújo MI \& Carvalho EM (2002). IgG anti-lgE autoantibodies in visceral leishmaniasis. Memórias do Instituto Oswaldo Cruz, 97: 101-103.

16. Bradwell AR, Stokes RP \& Mead GP (1995). Atlas of HEp-2 Patterns. The Binding Site Ltd., Birmingham, UK.

17. Morton S, Palmer B, Muir K \& Powell RJ (1998). IgE and non-lgE mediated allergic disorders in systemic lupus erythematosus. Annals of the Rheumatic Diseases, 57: 660-663.

18. McPhaul Jr JJ, Newcomb RW, Mullins JD, Thompson Jr AL, Lordon RE \& Rogers PW (1974). Participation of immunoglobulin E (lgE) in immune-mediated glomerulonephritis. Kidney International, 5: 292 299.

19. Tuma SN, Llach F, Sostrin S, Dubois EL \& Massry G (1981). Glomerular lgE deposits in patients with lupus nephritis. American Journal of Nephrology, 1: 31-36.

20. Millauer N, Zuercher AW, Miescher SM, Gerber HA, Seitz M \& Stadler BM (1999). High IgE in rheumatoid arthritis (RA) patients is complexed with anti-IgE autoantibodies. Clinical and Experimental Immunology, 115: 183-188. 